\section{Inactivation of heat adapted and chlorine adapted Listeria monocytogenes ATCC 7644 on tomatoes using sodium dodecyl sulphate, levulinic acid and sodium hypochlorite solution}

\author{
Oluwatosin Ademola Ijabadeniyi, \\ Elizabeth Mnyandu
}

Department of Biotechnology and Food Technology, Durban University of Technology, Durban, South Africa

\section{Abstract \\ The effectiveness of sodium dodecyl} sulphate (SDS), sodium hypochlorite solution and levulinic acid in reducing the survival of heat adapted and chlorine adapted Listeria monocytogenes ATCC 7644 was evaluated. The results against heat adapted L. monocytognes revealed that sodium hypochlorite solution was the least effective, achieving log reduction of 2.75, 2.94 and $3.97 \mathrm{log}$ colony forming unit (CFU)/mL for 1,3 and 5 minutes, respectively. SDS was able to achieve $8 \log$ reduction for both heat adapted and chlorine adapted bacteria. When used against chlorine adapted $L$. monocytogenes sodium hypochlorite solution achieved log reduction of 2.76, 2.93 and $3.65 \log \mathrm{CFU} / \mathrm{mL}$ for 1,3 and $5 \mathrm{~min}-$ utes, respectively. Using levulinic acid on heat adapted bacteria achieved log reduction of 3.07, 2.78 and $4.97 \log \mathrm{CFU} / \mathrm{mL}$ for 1, 3, 5 minutes, respectively. On chlorine adapted bacteria levulinic acid achieved log reduction of $2.77,3.07$ and $5.21 \mathrm{log}$ $\mathrm{CFU} / \mathrm{mL}$ for 1,3 and 5 minutes, respectively. Using a mixture of $0.05 \%$ SDS and $0.5 \%$ levulinic acid on heat adapted bacteria achieved $\log$ reduction of $3.13,3.32$ and $4.79 \log \mathrm{CFU} / \mathrm{mL}$ for 1,3 and 5 minutes while on chlorine adapted bacteria it achieved 3.20, 3.33 and 5.66 $\log \mathrm{CFU} / \mathrm{mL}$, respectively. Increasing contact time also increased $\log$ reduction for both test pathogens. A storage period of up to 72 hours resulted in progressive log reduction for both test pathogens. Results also revealed that there was a significant difference $(\mathrm{P} \leq 0.05)$ among contact times, storage times and sanitizers. Findings from this study can be used to select suitable sanitizers and contact times for heat and chlorine adapted L. monocytogenes in the fresh produce industry.

\section{Introduction}

There has been an increased consumption of fresh and minimally processed vegetables in recent years because of their many potential benefits. However as a result of the fact that contamination of fresh produce with pathogens can take place during pre-harvest and post-harvest, they have been implicated in food borne outbreaks (Johnston et al., 2006). Tomato contaminated with L. monocytogenes was reported to have caused listeriosis in 1979 in USA (Ijabadeniyi, unpublished thesis). Prazak et al. (2002) studied the prevalence of $L$. monocytogenes during the production and post-harvest processing of cabbage and they found that from 425 cabbage, 205 water and 225 environment sponge samples examined, L. monocytogenes was isolated from $3 \%$ of all samples. Twenty of these isolates were obtained from cabbage, three from water samples and another three were environmental sponge samples of packing shed surfaces. Furthermore, tomato with Salmonella spps has caused food borne outbreaks in 1990, 1993 and 2007 respectively in USA (Ijabadeniyi, unpublished thesis).

Causative bacterial pathogens especially Listeria monocytogenes, E. coli O157:H7 and Salmonella spp which have been implicated are able to cause infections because they are resistant to sanitizers, they have low ineffective dose, they form biofilms and they are able to adapt to stress (Ijabadeniyi, unpublished thesis). Food borne pathogens encounter various stress factors in food processing. These may result in pathogens developing resistance towards stress inducers over time (Battesti et al., 2011). Pathogens are able to adapt to environmental stress factors such as cold, acid, heat, starvation and osmotic stress (Soni et al., 2011). These environments are inherent in food manufacturing units. During food production, pathogens adapt to repeated use of sanitising chemicals, heat, temperature changes and substrate changes (Bridier et al., 2011).

Adaptation may also be due to intrinsic factors (Moorman et al., 2008). When bacteria adapt to a particular environment, they further develop cross protection for other stress factors, and this is when a pathogen develops further extended protection towards multiple stressors (Ágoston, 2009). Cross protection is a defence mechanism employed by bacteria to several other stresses including various food preservation techniques.

Exposure of bacteria to sub-lethal doses of the same stressor also results in increased resistance to subsequent lethal treatment of the same stressor (Bridier et al., 2011). De
Correspondence: Oluwatosin Ademola Ijabadeniyi, Department of Biotechnology and Food Technology, Durban University of Technology, Durban, South Africa.

Tel: +273.13735310

E-mail: oluwatosini@dut.ac.za

Key words: Tomato; Listeria monocytogenes; Sanitizers.

Received for publication: 7 April 2016. Revision received: 22 December 2016. Accepted for publication: 22 December 2016.

This work is licensed under a Creative Commons Attribution-NonCommercial 4.0 International License (CC BY-NC 4.0).

CCopyright O.A. Ijabadeniyi and E. Mnyandu, 2017 Licensee PAGEPress, Italy

Italian Journal of Food Safety 2017; 6:5916 doi:10.4081/ijfs.2017.5916

Angelis and Gobbetti (2004) termed this as limited response. Ágoston (2009) found that L. monocytogenes exhibits unique physiological, genomic, and proteomic responses when exposed to sub-lethal temperatures and developed resistance to subsequent lethal heat treatment. Arku et al. (2011) found that Cronobacter spp. survived better at lethal temperature of $52^{\circ} \mathrm{C}$ after adaptation at $46^{\circ} \mathrm{C}$ for 30 minutes. Bacterial cells may also develop general stress resistance. The general stress response is regulated by sigma factors. During nutrient deprivation and stress cells increase the accumulation of sigma factor RpoS. RpoS-dependent gene expression leads to general stress resistance of cells (Battesti et al., 2011).

Heat resistance in L. monocytogenes is influenced by factors such as strain variation, previous growth conditions, prior exposure to heat shock, acid stressor or other stressors (Bridier et al., 2011; Ágoston, 2009; Moorman et al., 2008). Heat resistance can occur during food processing especially in foods that require prolonged heating at low temperatures. Heating processes induces the production of heat shock proteins (HSPs). When temperatures are elevated, genes for hsp70 and hsp90 encode proteins which increase heat resistance. Incubation temperature also determines the extent of heat shock tolerance (Hu et al., 2007).

Pathogens that have been repeatedly exposed to sanitizers also develop resistance to subsequent treatment with the same sanitizer or different sanitizers especially when used below recommended concentrations. Resistance to sanitizers such as quaternary ammonium compounds is associated with $m d r L$ gene which encodes efflux 
pumps responsible for sanitizer resistance (Gandhi and Chikindas, 2007). Studies revealed that Staphylococcus aureus has an effective efflux system that confers resistance to QAC sanitizers (Smith et al., 2008). The same results were observed with trichlosan and chlorhexidine (Villagra et al., 2008).

The objective of this study was to determine the effectiveness of sodium dodecyl sulphate (SDS), levulinic acid and sodium hypochlorite solution in reducing the presence of heat adapted and sodium hypochlorite solution adapted L. monocytogenes on tomatoes.

\section{Materials and methods}

\section{Materials}

\section{Fresh produce}

Tomatoes were purchased from a local supermarket on three separate occasions in Durban South Africa. On the day of purchase the tomatoes were washed in running water. The tomatoes were again washed in $70 \%$ ethanol (Ijabadeniyi et al., 2011). Prior to inoculation with test organism and treatment with sanitizers (see 2.1.3), the tomatoes were tested for the presence of L. monocytogenes.

\section{Bacterial strains}

Listeria monocytogenes ATCC 7644 (Merck, South Africa) was used for this study. The strain was cultured in Fraser broth for 24 hours at $37^{\circ} \mathrm{C}$ and stored at $4^{\circ} \mathrm{C}$ (Ijabadeniyi et al., 2011a). Prior to each experiment, a fresh culture of $8 \mathrm{log}$ $\mathrm{CFU} / \mathrm{mL}$ of $L$. monocytogenes was prepared using McFarland Standards from the stock culture by sub culturing in Fraser broth for 24 hours at $37^{\circ} \mathrm{C}$ (Ji et al., 2010).

\section{Sanitizers}

Sodium dodecyl sulphate (SDS), levulinic acid, sodium hypochlorite solution, all purchased from Merck, South Africa were tested, individually or combined with contact times (1, 3, 5 minutes); for their killing effect on L. monocytogenes in tomatoes. The sanitizers were used as follows: $1 \%$ SDS individually; $0.5 \%$ Levulinic acid individually; 200 ppm Sodium hypochlorite solution individually; $0.5 \%$ levulinic acid $/ 0.05 \%$ SDS mixture.

Zhao et al. (2009) have successfully used the combination of SDS and Levulinic acid to inactivate Salmonella and E. coli O157: H7 on lettuce and poultry. Sodium hypochlorite solution is routinely used in the fresh produce industry.

\section{Methods}

\section{Preparation of heat adapted Listeria monocytogenes}

The method of Ágoston (2009) was followed except that Fraser Broth was used in place of Brain Heart Infusion. A fresh culture of L. monocytogenes ATCC 7644 was grown in Fraser broth for 24 hours at $37^{\circ} \mathrm{C}$. The cultures were harvested by centrifugation at $4000 \mathrm{rpm}$ for 5 minutes at $4{ }^{\circ} \mathrm{C}$. The pellets were washed twice in phosphate buffer ( $\mathrm{pH}$ 6.8) to remove unspent media and inoculated gradually into Tryptone Soy Broth (pH 7.3) to yield a population of $10^{8}$ CFU/mL using the McFarlan standard (Ji et al., 2010). Proportions of $1 \mathrm{~mL}$ were transferred to $1.5 \mathrm{~mL}$ Epperndorf tubes. The samples were submerged in thermostatically controlled water bath at $60^{\circ} \mathrm{C}$ for $15 \mathrm{~min}$ utes. Immediately after heat treatment, samples were transferred to an ice bath to cool them and then sanitised using 70\% alcohol after which cell vitality was assessed. The suspensions were used to inoculate tomatoes as detailed below. Three replicate experiments were done for each trial and a fresh suspension was prepared for each trial.

\section{Preparation of chlorine adapted Listeria monocytogenes}

The method of Taormina and Beuchat (2001) was followed. A fresh culture of $L$. monocytogenes was grown overnight in Tryptose phosphate broth. A $25 \mathrm{~mL}$ culture was dispensed into a $50 \mathrm{~mL}$ centrifuge tube and centrifuged at $5000 \mathrm{rpm}$ for 10 minutes at $4{ }^{\circ} \mathrm{C}$. Pellets were then washed three times in pre-cooled potassium phosphate buffer ( $\mathrm{pH} 7.1$ ) and re-suspended in $25 \mathrm{~mL}$ of phosphate buffer. Cells of L. monocytogenes $(10 \mathrm{~mL})$ were added to $50 \mathrm{~mL}$ of 6 ppm of $12.5 \% \mathrm{w} / \mathrm{v}$ sodium hypochlorite. After 5 minutes $10 \mathrm{~mL}$ were drawn and neutralised by adding into $30 \mathrm{~mL}$ of $0.01 \mathrm{~N}$ sodium thiosulphate solution and vortexing for 10 seconds after which cell vitality was accessed. The suspensions were used to inoculate tomatoes as detailed below. Three replicate experiments were done for each trial and a fresh suspension was prepared for each trial.

\section{Inoculation of bacterial strains into tomatoes}

As implemented by Zhao et al. (2009), a $25 \mathrm{~g}$ sample of tomatoes was cut into approximately $5 \mathrm{~cm}$ long pieces in the lamina flow hood. The samples were submerged into bacterial suspension (either heat adapted or chlorine adapted) $\left(10^{8}\right.$ $\mathrm{CFU} / \mathrm{mL}, 50 \mathrm{~mL}$ of bacterial solution into $950 \mathrm{~mL}$ of distilled water) for 60 seconds and then air dried for 20 minutes in the lamina flow hood. The samples were then sus- pended into $500 \mathrm{~mL}$ test solutions and agitated by a magnetic stirrer at $100 \mathrm{rpm}$ for 1 , 3, 5 minutes. Following treatment, the samples were placed in double zipper bags containing $25 \mathrm{~mL}$ of phosphate buffered saline and pummelled for one minute. The suspension was serially diluted $(1: 10)$ in $0.1 \%$ buffered peptone water and enumerated for L. monocytogenes ATCC 7644.

\section{Enumeration of Listeria monocytogenes}

In line with Taormina and Beuchat (2001) experimental methodology, populations of L. monocytogenes ATCC 7644 were determined by surface plating serially diluted samples; $0.1 \mathrm{~mL}$ in duplicates on Listeria Selective Agar (Oxoid Ltd, Wade Road, Basingstoke, Hants, UK). The treated samples were kept at $4^{\circ} \mathrm{C}$ and analysed at 0,24 , 48 and 72 hours for assessment. Plates were incubated for 24 hours at $37^{\circ} \mathrm{C}$ after which colonies were counted using a colony counter.

\section{Data analysis}

Three trials were conducted for each experiment for the purposes of reducing the margin of error, thereby improving the quality of the results. Data was analysed using SPSS version 21 (IBM Statistics). Analysis of variance was conducted with repeated measures and Greenhouse Geisser correction to study the effect of contact time on the survival of adapted L. monocytogenes, ATCC 7644 and the effect of each sanitizer on the survival of adapted L. monocytogenes ATCC 7644 at varied storage time intervals $(0,24,48$ and 72 hours). The number of surviving LM was plotted against contact time (1, 3 and 5 minutes) and also against time interval $(0,24,48$ and 72 hours). Log reduction for each contact time and sanitizer was also calculated and presented in a table. Pairwise comparison with Bonferroni adjustment was used to determine any significance difference between treatments.

\section{Results}

\section{Effect of sanitizer treatments and storage time intervals on the survival of heat adapted and chlorine adapted Listeria monocytogenes}

Three trials were conducted for this study and means determined as shown in Table 1 . The mean values show the surviving heat and chlorine adapted Listeria. The heat adapted bacteria was more resistant to the sanitizer compared to the chlorine adapted bacteria. However; the difference 
between the mean of surviving bacteria for heat adapted and chlorine adapted bacteria was not significant.

The surviving bacteria were also stored for $0,24,48$ and 72 hour series so as to assess the effect of storage time on surviving LM. Varying storage time intervals reduced both heat adapted bacteria $(\mathrm{P} \leq 0.05)$. A progressive reduction in surviving bacteria was observed for both heat adapted and chlorine adapted bacteria.

\section{Effect of sanitizer contact time on} heat adapted and chlorine adapted Listeria monocytogenes ATCC 7644

Increasing sanitizer contact time reduced the survival of both heat adapted and chlorine adapted L. monocytogenes. Among the tested sanitizers, SDS destroyed all the bacteria. Marginal means were plotted in Figure 1 to show the means of surviving bacteria for each sanitizer and contact time.

\section{Overall log reductions}

Overall log reduction of surviving bacteria for the entire storage period were also calculated (Table 2). Heat adapted bacteria were reduced by approximately $2.75,3.13$ and $2.78 \log \mathrm{CFU} / \mathrm{mL}$ when exposed to sodium hypochlorite solution, mixture and

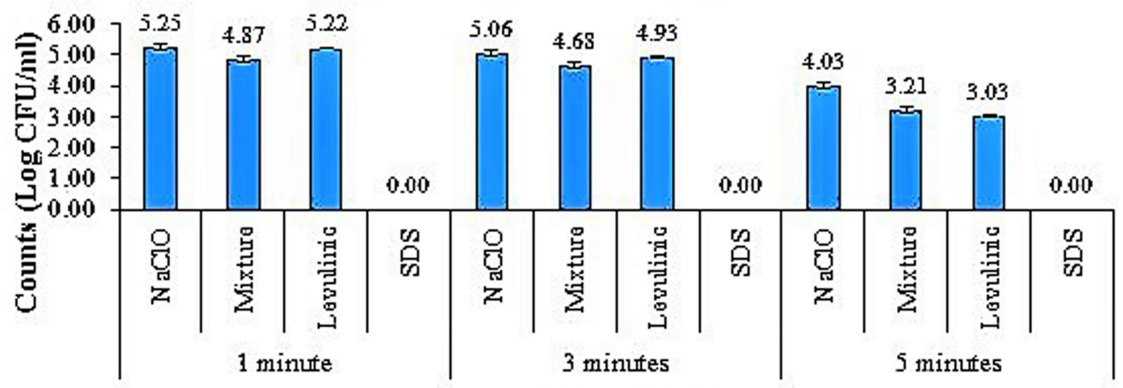

Contact time (minutes)

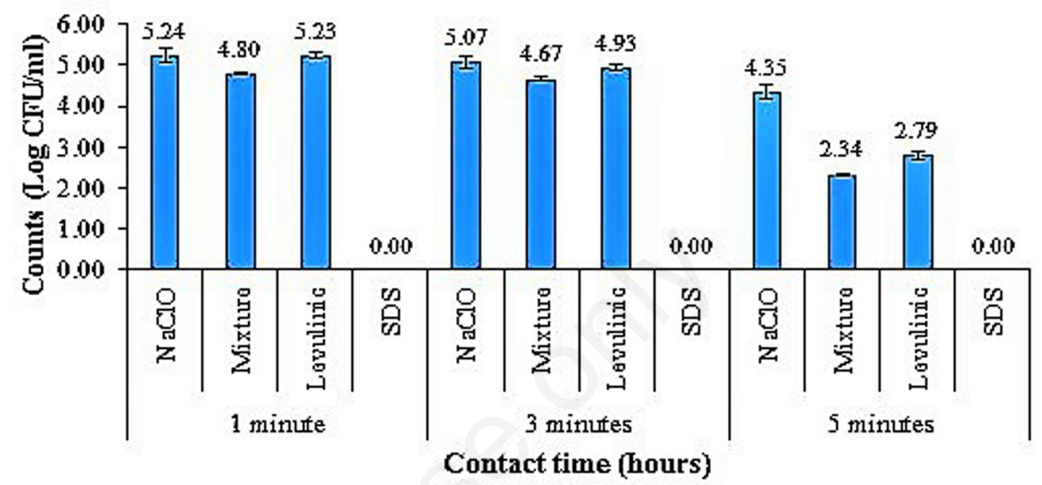

Figure 1. Means of surviving heat (A) and chlorine adapted Listeria monocytogenes (B).

Table 1. Mean bacterial count of heat and chlorine adapted Listeria monocytogenes ATCC 7644 after treatment with different sanitizers at different contact times.

\begin{tabular}{|c|c|c|c|c|c|}
\hline Sanitizer & Contact time (min) & $0 \mathrm{~h}$ & $24 \mathrm{~h}$ & $48 \mathrm{~h}$ & $72 \mathrm{~h}$ \\
\hline \multicolumn{6}{|c|}{ Heat adapted Listeria monocytogenes ATCC 7644} \\
\hline \multirow[t]{3}{*}{$\mathrm{NaClO}$} & 1 & $5.42 \pm 0.01$ & $5.37 \pm 0.01$ & $5.27 \pm 0.04$ & $4.94 \pm 0.04$ \\
\hline & 3 & $5.25 \pm 0.01$ & $5.10 \pm 0.02$ & $5.04 \pm 0.03$ & $4.85 \pm 0.03$ \\
\hline & 5 & $5.17 \pm 0.06$ & $4.17 \pm 0.45$ & $4.10 \pm 0.45$ & $2.67 \pm 0.06$ \\
\hline \multirow[t]{3}{*}{ Mixture } & 1 & $5.03 \pm 0.01$ & $4.93 \pm 0.03$ & $4.81 \pm 0.06$ & $4.72 \pm 0.08$ \\
\hline & 3 & $4.77 \pm 0.04$ & $4.73 \pm 0.04$ & $4.61 \pm 0.02$ & $4.59 \pm 0.07$ \\
\hline & 5 & $3.87 \pm 0.12$ & $3.47 \pm 0.59$ & $2.80 \pm 0.70$ & $2.70 \pm 0.10$ \\
\hline \multirow[t]{3}{*}{ Levulinic } & 1 & $5.28 \pm 0.02$ & $5.22 \pm 0.02$ & $5.21 \pm 0.01$ & $5.18 \pm 0.01$ \\
\hline & 3 & $5.23 \pm 0.01$ & $4.99 \pm 0.09$ & $4.86 \pm 0.09$ & $4.65 \pm 0.08$ \\
\hline & 5 & $4.20 \pm 0.00$ & $3.77 \pm 0.15$ & $2.67 \pm 0.06$ & $1.50 \pm 0.10$ \\
\hline \multirow[t]{3}{*}{ SDS } & 1 & 0.00 & 0.00 & 0.00 & 0.00 \\
\hline & 3 & 0.00 & 0.00 & 0.00 & 0.00 \\
\hline & 5 & 0.00 & 0.00 & 0.00 & 0.00 \\
\hline \multicolumn{6}{|c|}{ Chlorine adapted Listeria monocytogenes ATCC 7644} \\
\hline \multirow[t]{3}{*}{$\mathrm{NaClO}$} & 1 & $5.42 \pm 0.01$ & $5.37 \pm 0.01$ & $5.21 \pm 0.02$ & $4.96 \pm 0.06$ \\
\hline & 3 & $5.22 \pm 0.02$ & $5.09 \pm 0.03$ & $5.02 \pm 0.02$ & $4.96 \pm 0.03$ \\
\hline & 5 & $5.23 \pm 0.06$ & $4.77 \pm 0.49$ & $4.13 \pm 0.8$ & $3.27 \pm 0.66$ \\
\hline \multirow[t]{3}{*}{ Mixture } & 1 & $5.00 \pm 0.03$ & $4.86 \pm 0.03$ & $4.76 \pm 0.04$ & $4.59 \pm 0.05$ \\
\hline & 3 & $4.76 \pm 0.04$ & $4.73 \pm 0.05$ & $4.60 \pm 0.04$ & $4.60 \pm 0.02$ \\
\hline & 5 & $2.90 \pm 0.10$ & $2.77 \pm 0.06$ & $2.17 \pm 0.37$ & $1.53 \pm 0.06$ \\
\hline \multirow[t]{3}{*}{ Levulinic } & 1 & $5.28 \pm 0.01$ & $5.24 \pm 0.01$ & $5.21 \pm 0.01$ & $5.18 \pm 0.01$ \\
\hline & 3 & $5.24 \pm 0.02$ & $4.96 \pm 0.03$ & $4.9 \pm 0.04$ & $4.63 \pm 0.08$ \\
\hline & 5 & $4.20 \pm 0.53$ & $3.37 \pm 0.49$ & $2.00 \pm 0.50$ & $1.60 \pm 0.10$ \\
\hline \multirow[t]{3}{*}{ SDS } & 1 & 0.00 & 0.00 & 0.00 & 0.00 \\
\hline & 3 & 0.00 & 0.00 & 0.00 & 0.00 \\
\hline & 5 & 0.00 & 0.00 & 0.00 & 0.00 \\
\hline
\end{tabular}

SDS, sodium dodecyl sulphate. Mean counts \pm standard deviation ( $\log _{10}$ colony forming unit/mL). Means were not significantly different $(\mathrm{P} \leq 0.05)$. 
levulinic acid, respectively. When the contact time was increased to 3 minutes, the log reduction also increased to 2.94, 3.32 and $3.07 \log \mathrm{CFU} / \mathrm{mL}$, respectively for sodium hypochlorite solution, mixture and levulinic acid. A further reduction in bacteria was achieved with a contact time of 5 minutes for all sanitizers.

Log reduction of 2.76, 3.20 and $2.77 \mathrm{log}$ $\mathrm{CFU} / \mathrm{mL}$ was achieved by exposing chlorine adapted L. monocytogenes to sodium hypochlorite solution, mixture and levulinic acid for 1 minute. Increasing contact time to 3 minutes increased the log reductions by 2.93, 3.33 and $3.07 \log \mathrm{CFU} / \mathrm{mL}$, respectively, while a contact time of 5 minutes achieved a $\log$ reduction of 3.65, 5.66 and $3.21 \log \mathrm{CFU} / \mathrm{mL}$. The $\log$ reduction for heat adapted bacteria were lower than those of chlorine adapted bacteria. This is evident that the chlorine adapted $L$. monocytogenes was more responsive to sanitizer stress compared to heat adapted bacteria. In all cases SDS achieved an $8 \log \mathrm{CFU} / \mathrm{mL}$ reduction.

\section{Discussion}

In this study, sodium hypochlorite solution, levulinic acid, a mixture of SDS and levulinicwere able to reduce the growth of both heat adapted and chlorine adapted $L$. monocytogenes ATCC 7644 while SDS eliminated them. Their actions on the pathogens were significantly different. Sodium hypochlorite solution was the least effective followed by levulinic acid and then SDS/Lev mixture. SDS was able to eradicate the adapted pathogens unlike the other sanitizers. Apart from temperature, concentration and contact time, effectiveness of sanitizer depends on the pathogen being treated (Beltrame et al., 2012; Moreno et al., 2012; Ding et al., 2011; Stebbins et al., 2011; Tornuk et al., 2011). The reports from previous researchers suggest the importance of taking extra care when selecting sanitizers to use against a particular pathogen. This work however showed that SDS may be preferred to chlorine since it was able to cause $8 \log$ reduction unlike the other sanitizers.

Heat adapted pathogens were more resistant to these sanitizers compared to the chlorine adapted pathogens. It has been reported that previously adapted pathogens are more resistant to subsequent stress (Ágoston, 2009) and that non-adapted pathogens are more susceptible to sanitizer stress compared to adapted pathogens (Gandhi and Chikindas, 2007). This was also confirmed in our earlier work using non-adapted L. momocytogenes (Mnyandu et al., 2015). Effects of heat adaptation, acid adaptation and sanitizer adaptation have also been widely reported. Studies have also shown that particularly in L. monocytogenes, resistance to sanitizer is caused by the presence of sigma B factor, a protein required for RNA synthesis (Ryan et al., 2008; Gandhi and Chikindas, 2007).

Other studies indicated that L. monocytogenes are resistant to alkaline stress at high temperatures (Taormina and Beuchat, 2001). Due to cross protection adapted cells were more stable to sanitizer treatment. Acid adaptation was also reported to increase the viability of $L$. monocytogenes and Salmonella spp. to other sanitizers (Lin et al., 2011). Another study showed that heat adapted $L$. innocua could not survive the action of cetrimide (Moorman et al., 2008). Neo et al. (2013) also reported similar results using peroxyacetic acid and sodium hypochlorite solution on bean sprouts. Lin et al. (2011) found that Vibrio parahaemolyticus was more resistant to chlorine-containing disinfectant (Clidox-S) and a quaternary ammonium compound (Quatricide) at 25 and $40^{\circ} \mathrm{C}$ after pre exposure to heat shock, cold shock and acid adaptation.

Kim et al. (2012) also found that acid adaptation of $C$. sakazakii by pre-exposure to acidic $\mathrm{pH}$ can enhance the resistance of cells against subsequent environmental stresses such as acidic $\mathrm{pH}$, heat, and organic acids. Another study by Mavri and Smole Možina (2012) using Campylobacter jejuni and Campylobacter coli also show an increased tolerance to sanitizers. Ethanol and isopropanol concentration of $70 \%$ reduced the infectivity of murine norovirus by $2.6 \log$ units, whereas 50 and $70 \%$ ethanol reduced the infectivity of feline calicivirus by $2.2 \log$ units after exposure for 5 min (Park et al., 2010). On the contrary Riazi and Matthews (2011) found that previously adapted pathogens were still susceptible to sanitizers.

Observations of this study are not different from previous studies that showed that the effect of sanitizers can be changed based on contact time with increasing contact time resulting in a decrease in viability of pathogens (Beltrame et al., 2012; Moreno et al., 2012; Ding et al., 2011; Mattson et al., 2011; Park et al., 2011; Tornuk et al., 2011). In this study increasing contact time significantly reduced surviving bacteria of either heat adapted or chlorine adapted L. monocytogenes. Through this study it was also established that adaptive treatments using sodium hypochlorite solution and heat separately can impose resistance on L. monocytogenes.

Some studies have shown that a 3 minute contact time is enough to destroy pathogens (Ding et al., 2011; Mattson et al., 2011; Stebbins et al., 2011), while other studies showed that a contact time of up to 10-15 minutes is required if pathogens are to be significantly reduced (Beltrame et al., 2012). Research using peracetic acid to remove Escherichia coli, Staphylococcus aureus, Streptococcus mutans, Candida albicans and Bacillus subtilus revealed that a contact time of 2 minutes can achieve satisfactory results (Salvia et al., 2011). In other studies using ozone, prolonging contact time to 5 minutes could not reduce $E$. coli effectively (Ölmez, 2010). Some studies have also indicated that contact time varies and depends on the pathogen under study (Park and Sobsey, 2011). It is important to consider carefully the contact time suitable for better results when using antimicrobials.

Table 2. $\mathrm{Log}$ reduction (colony forming unit $/ \mathrm{mL}$ ) for all sanitizers at 1,3 and 5 minutes: heat and chlorine adapted Listeria monocytogenes.

\begin{tabular}{lccc} 
Sanitiver & 1 minute & 3 minutes & 5 minutes \\
& Overall log reduction of heat adapted Listeria monocytogenes \\
NaClO & 2.75 & 2.94 & 3.97 \\
Mixture & 3.13 & 3.32 & 4.79 \\
\hline Levulinic & 2.78 & 3.07 & 4.97 \\
SDS & 8.00 & 8.00 & 8.00 \\
\hline & Overall log reduction of chlorine adapted Listeria monocytogenes \\
NaClO & 2.76 & 2.93 & 3.65 \\
Mixture & 3.20 & 3.33 & 5.66 \\
\hline Levulinic & 2.77 & 3.07 & 5.21 \\
SDS & 8.00 & 8.00 & 8.00 \\
\hline
\end{tabular}

SDS, sodium dodecyl sulphate. 
Varying the storage time period up to 72 hours resulted in progressive reduction in surviving heat adapted and chlorine adapted $L$. monocytogenes. In other studies, growth was observed only for the samples stored at $22^{\circ} \mathrm{C}$ for 18 hours, whereas in the rest of the incubation conditions no significant change in the $E$. coli count was observed (Ölmez, 2010). Although this study did not determine the effect of sanitizers on organoleptic properties or antioxidant capability, a study by Ruiz-Cruz et al. (2010) revealed that sanitizers were capable of controlling microbial growth without resulting in major loss of antioxidant capacity and photochemical characteristics after a storage period of 27 days. Similar results were reported by Tomás-Callejas et al. (2011) using 40,70 or $100 \mathrm{mg} \mathrm{L}^{-1}$ free chlorine, neutral and acidic electrolyzed water on fresh-cut mizuna bay leaves for 11 days at $5^{\circ} \mathrm{C}$.

\section{Conclusions}

Exposure to stress conditions causes resistance of $L$. monocytogenes to sanitizers with heat offering a higher protection than chlorine. Sodium hypochlorite solution and levulinic acid were able to cause a significant reduction in the microbial populations of the adapted L. monocytogenes in tomatoes. While SDS was able to totally inactivate the pathogens, Levulinic acid and mixture of SDS and Levulinic achieved greater log reduction as compared to sodium hypochlorite solution. Contact time can be increased to improve the effectiveness of sanitizers, however extra care should be taken not to cause negative impact on the sensory properties of fresh produce. Findings from this study can be used to select suitable sanitizers and contact times for treatment of adapted pathogens in the produce industry.

\section{References}

Ágoston R, 2009. Understanding stress adaptive response in Listeria monocytogenes. PhD School of Food Science, Budapest Corvinus Egyetem. Available from: phd.lib.unicorvinus.hu/426/1/agoston reka.pdf

Arku B, Fanning S, Jordan K, 2011. Heat adaptation and survival of Cronobacter spp. (formerly Enterobacter sakazakii). Foodborne Pathog Dis 8:975-81.

Battesti A, Majdalani N, Gottesman S, 2011. The RpoS-mediated general stress response in Escherichia coli. Annu Rev Microbiol 65:189-213.

Beltrame, CA, Kubiak, GB, Lerin, LA,
Rottava I, Mossi AJ, Oliveira DD, Cansian RL, Treichel H, Toniazzo G, 2012. Influence of different sanitizers on food contaminant bacteria: effect of exposure temperature, contact time, and product concentration. Ciência Tecnol Alime 32:228-32.

Bridier A, Briandet, R, Thomas, V, DuboisBrissonnet F, 2011. Resistance of bacterial biofilms to disinfectants: a review. Biofouling 27:1017-32.

De Angelis M, Gobbetti M, 2004. Environmental stress responses in Lactobacillus: a review. Proteomics 4:106-22.

Ding T, Rahman SME, Deog-Hwan OH, 2011. Inhibitory effects of low concentration electrolyzed water and other sanitizers against foodborne pathogens on oyster mushroom. Food Control 22:318-22.

Gandhi M, Chikindas ML, 2007. Listeria: a foodborne pathogen that knows how to survive. Int J Food Microbiol 113:1-15.

$\mathrm{Hu}$ Y, Raengpradub S, Schwab, U, Loss, C, Orsi RH, Wiedmann M, Boor KJ, 2007. Phenotypic and transcriptomic analyses demonstrate interactions between the transcriptional regulators $\mathrm{CtsR}$ and Sigma B in Listeria monocytogenes. Appl Environ Microb 73:7967-80.

Ijabadeniyi OA, Debusho LK, Vanderlindee M, Buys EM, 2011. Irrigation water as a potential preharvest source of bacterial contamination of vegetables. J Food Safety 31:452-61.

Ji QX, Zhao QS, Deng J, Lü R, 2010. A novel injectable chlorhexidine thermosensitive hydrogel for periodontal application: preparation, antibacterial activity and toxicity evaluation. J Mater Sci Mater Med 21:2435-42.

Johnston LM, Moe CL, Moll D, Jaykus L, 2006. The epidemiology of produceassociated outbreaks of foodborne disease. In: J. James. (ed.) Microbial hazard identification in fresh fruits and vegetables. John Wiley, Hoboken, NJ, USA, chapter 4.

Kim SJ, Bae, YM, Lee SY, 2012. Stress response of acid-shocked Cronobacter sakazakii against subsequent acidic $\mathrm{pH}$, mild heat, and organic acids. Food Sci. Biotechnol 21:205-10.

Lin MH, Lee SL, Chou CC, 2011. Acid adaptation affects the viability of Listeria monocytogenes BCRC 14846 and Salmonella typhimurium BCRC 10747 exposed to disinfectants at $25^{\circ} \mathrm{C}$ and $40^{\circ} \mathrm{C}$. Foodborne Pathog Dis 8:1077-81.

Mattson TE, Johny AK, Amalaradjou MAR, More K, Schreiber DT, Patel J, Venkitanarayanan K, 2011. Inactivation of Salmonella spp. on tomatoes by plant molecules. Int $\mathrm{J}$ Food Microbiol 144:464-8.

Mavri A, Smole Možina S, 2012. Development of antimicrobial resistance in Campylobacter jejuni and Campylobacter coli adapted to biocides. Int J Food Microbiol 160:304-12.

Mnyandu E, Ijabadeniyi O, Singh S, 2015. Inactivation of Listeria monocytogenes ATCC 7644 on tomatoes using Sodium Dodecyl Sulphate, Levulinic Acid and Sodium Hypochlorite Solution. Ital J Food Sci 27:1-10.

Moorman MA, Thelemann CA, Zhou S, Pestka JJ, Linz JE, Ryser ET, 2008. Altered hydrophobicity and membrane composition in stress-adapted Listeria innocua. J Food Protect 71:182-5.

Moreno Y, Sanchez-Contreras J, Montes RM, García-Hernández J, Ballesteros L, Ferrús MA, 2012. Detection and enumeration of viable Listeria monocytogenes cells from ready-to-eat and processed vegetable foods by culture and DVC-FISH. Food Control 27:3749.

Neo SY, Lim PY, Phua LK, Khoo GH, Kim SJ, Lee SC, Yuk HG, 2013. Efficacy of chlorine and peroxyacetic acid on reduction of natural microflora, Escherichia coli O157: H7, Listeria monocyotgenes and Salmonella spp. on mung bean sprouts. Food Microbiol $36: 475-80$.

Ölmez H, 2010. Effect of different sanitizing methods and incubation time and temperature on inactivation of Escherichia coli on lettuce. J Food Safety 30:288-99.

Park GW, Barclay L, Macinga D, Charbonneau D, Pettigrew CA, Vinje J, 2010. Comparative efficacy of seven hand sanitizers against murine norovirus, feline calicivirus, and GII. 4 norovirus. J Food Protect 73:2232-8.

Park GW, Sobsey MD, 2011. Simultaneous comparison of murine norovirus, feline calicivirus, coliphage MS2, and GII. 4 norovirus to evaluate the efficacy of sodium hypochlorite against human norovirus on a fecally soiled stainless steel surface. Foodborne Pathog Dis 8:1005-10

Prazak AM, Murano EA, Mercado I, Acuff GR, 2002. Prevalence of Listeria monocytogene during production and postharvest processing of cabbage. J Food Protect 65:1728-34.

Riazi S, Matthews KR, 2011. Failure of foodborne pathogens to develop resistance to sanitizers following repeated exposure to common sanitizers. Int Biodeterior Biodegradation 65:374-8. 